\title{
Activity and Safety Recognition using Smart Work Shoes for Construction Worksite
}

\author{
Changwon Wang ${ }^{1,4}$, Young Kim ${ }^{2}$, Seung Hyun Lee ${ }^{3}$, Nak-Jun Sung ${ }^{4}$, Se Dong Min ${ }^{1,4, *}$ \\ and Min-Hyung $\mathrm{Choi}^{5}$ \\ ${ }^{1}$ Department of Medical IT Engineering, Soonchunhyang University, Asan, 31538, Korea \\ [e-mail: changwon@sch.ac.kr, sedongmin@sch.ac.kr] \\ ${ }^{2}$ Wellness Coaching Service Research Center, Soonchunhyang University, Asan, 31538, Korea \\ [e-mail: ykim02@sch.ac.kr] \\ ${ }^{3}$ School of Architecture Engineering, Hongik University, Sejong, 30016, Korea \\ [e-mail: slee413@hongik.ac.kr] \\ ${ }^{4}$ Department of Computer Science, Soonchunhyang University, Asan, 31538, Korea \\ [e-mail: njsung@sch.ac.kr] \\ ${ }^{5}$ Department of Computer Science and Engineering, University of Colorado Denver, Colorado, USA \\ [e-mail: Min.Choi@ucdenver.edu] \\ *Corresponding author: Se Dong Min
}

Received March 26, 2019; revised Septebmer 17, 2019; accepted November 6, 2019; published February 29, 2020

\begin{abstract}
Workers at construction sites are easily exposed to many dangers and accidents involving falls, tripping, and missteps on stairs. However, researches on construction site monitoring system to prevent work-related injuries are still insufficient. The purpose of this study was to develop a wearable textile pressure insole sensor and examine its effectiveness in managing the real-time safety of construction workers. The sensor was designed based on the principles of parallel capacitance measurement using conductive textile and the monitoring system was developed by C\# language. Three separate experiments were carried out for performance evaluation of the proposed sensor: (1) varying the distance between two capacitance plates to examine changes in capacitance charges, (2) repeatedly applying $1 \mathrm{~N}$ of pressure for 5,000 times to evaluate consistency, and (3) gradually increasing force by $1 \mathrm{~N}$ (from $1 \mathrm{~N}$ to $46 \mathrm{~N}$ ) to test the linearity of the sensor value. Five subjects participated in our pilot test, which examined whether ascending and descending the stairs can be distinguished by our sensor and by weka assessment tool using k-NN algorithm. The 10 -fold cross-validation method was used for analysis and the results of accuracy in identifying stair ascending and descending were $87.2 \%$ and $90.9 \%$, respectively. By applying our sensor, the type of activity, weight-shifting patterns for balance control, and plantar pressure distribution for postural changes of the construction workers can be detected. The results of this study can be the basis for future sensor-based monitoring device development studies and fall prediction researches for construction workers.
\end{abstract}

Keywords: Construction site, Worker, Safety, Conductive textile, Stairs 


\section{Introduction}

Construction industry is highly dependent on labor force and construction worker's safety is directly related to productivity. However, the workers at construction sites are at high risk of getting injured or dying from external causes. Workers at construction sites are frequently exposed to many types of dangers involving falls, tripping, and missteps on the stairs. A study by Kenneth et al. reported that 309,060 cases of injuries were from falls, and that number is higher than the injuries from contact with objects and equipment [1]. According to the Bureau of Labor Statistics (BSL) Survey of Occupational Injuries and Illnesses (SOII) in 2015, falls accounted for $26.8 \%$ of all injuries. Courtney et al. documented work-related disability and death due to falls at construction sites and reported that the common cause was the stairs at the work sites that often lack firm surface and railings [2]. Danger detection and warning system for construction work site is crucially needed to reduce and prevent such tragedies.

Industrial safety includes securing the safety of workplace since construction materials, machinery, and devices can cause accidents [3]. Although the importance of managing the safety of construction workers is raised every year, there still are very few studies on this matter. Falling accidents have long been recognized as an important occupational safety issue, because they not only directly affect work speed and performance but also are the main causes of death or injury at the construction sites [4-6]. Stairway falls in general are one of the global health concerns and are often associated with extensive damages and injuries with poor prognosis $[7,8]$. Previous studies reported that falls from the stairs lead to accidental deaths in older adults and to the coincident activity for $7-36 \%$ of falls $[9,10]$. Most of the fall-related accidents were reported to be in high teens or low twenties [11-17] and appeared particularly evident for the middle-aged adults [15-17]. Since the age range of construction workers is wide, personal protective equipment (PPE) practical for people of all ages is needed.

Traditional types of PPE include safety helmet, worker, gloves, work pants, shirts, and glasses. Among these, wearing safety helmet and safety shoes is essential for workers' safety. With emerging technology, several studies developed smart safety helmets using accelerometer sensor for fatigue detection and safety shoes with pressure sensors [18,19]. A study by Yang et al. [20] assessed gait in a laboratory to identify fall harzards of construction envrionments using accelerometer sensor and motion capture system.

Other studies tested the effect of safety training and education for construction workers in recognizing and identifying risks [21,22]. However, risk detection relied on the judgment of a subjective and error prone person due to his or her knowledge and experience of various levels of risk conditions. Construction sites are dynamic, adding to the complexity of detecting hazards, especially in low light or noisy conditions. Considering this, additional approaches are needed to address the current limitations to improve risk identification at construction sites. Recent attention has been paid to the researches on the safety monitoring of the operator using wearable pressure sensor, acceleration sensor, and gyroscope.

Some authors focused on detecting a fall risk before it occurs in humans and robots [23-25]. However, these are highly focused in threshold based algorithms, and therefore very subject dependent. To monitor movement execution in real time and to prevent falls during daily life activities, a study by Ribeiro et al. (2019) developed an offline IMU-based classifier capable of distinguishing normal gait from fall and pre-fall situations [26].

Along with various high-functioning and user-friendly sensors, a systematic management system is now needed to monitor and warn the construction workers of the dangers they face at the worksites. Although needed, setting up real-time monitoring systems at construction sites 
with commercial sensors, motion detecting cameras, wired computers, and general alarming programs would be quite costly and inefficient for the workers. A cost-effective, nonrestrictive sensors and real-time warning system are essential to reduce accidents and life-threatening injuries that occur at construction work sites. Thus, this study developed inexpensive but high-functioning wireless sensor and monitoring system for fall detection.

Many studies have performed motion analysis on daily activities and gait of various patients and healthy individuals [24,25,27-31], but not much research has focused on the causes and preventions for falling accidents from stairway at construction work sites. Moreover, development of wireless activity-monitoring sensors with real-time accident warning system for construction workers are rarely found in literature.

Therefore in this study, a wireless, lightweight, wearable textile insole pressure sensor for real-time safety monitoring system was developed to overcome and complement the limitations of commercial sensing systems. Performance and feasibility of the developed sensor were tested. Our sensor was designed to detect weight-shifting patterns and plantar pressure distribution changes during gait, ascending, and descending the stairs. Respective analysis of balance and postural changes during activities can be used to warn the workers when any extreme movements out of normal range of motion are detected.

\section{Methods}

\subsection{Textile-based pressure sensor}

A pressure sensor was developed by applying a parallel capacitance measurement method using conductive textile as shown in Fig. 1. For the sensor, W-290-PCN model (A-jin Electron, Gangseo, Busan, Republic of Korea) was used. The W-290-PCN model is consisted of polyester, sequentially-plated with nickel, copper, and nickel.

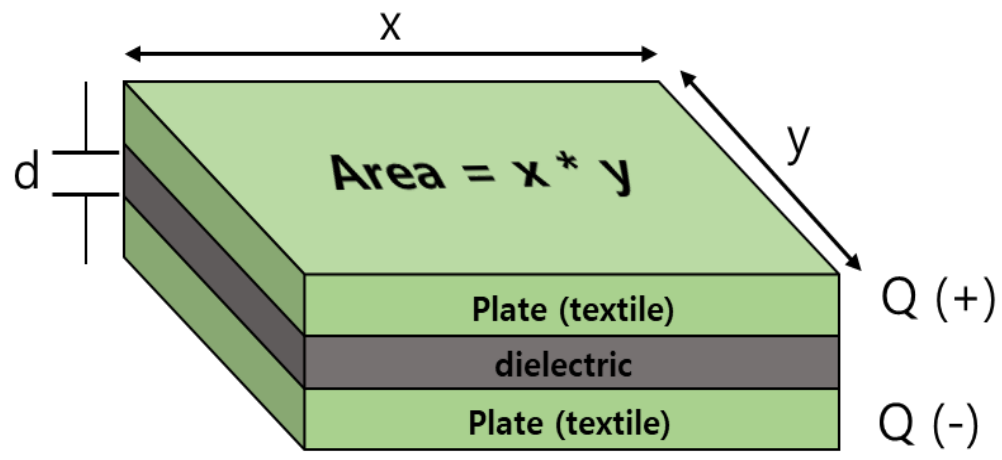

Fig. 1. Structure of a parallel capacitor

A capacitor is made of two conductive plates that are separated by a dielectric material. The plates accumulate electric charge; positive charge in one plate and negative charge in the other plate and it is measured in units of Farad (F). $1 \mathrm{~F}$ is the capacitance of $1 \mathrm{C}$ charge stored at both ends of the conductor plate at a voltage of $1 \mathrm{~V}$. Capacitance refers to the amount of charge per unit voltage a capacitor can store across a conductor plate and the parallel capacitance can be calculated by Equation (1).

$$
C=\frac{Q}{V}=\varepsilon \frac{A}{d}
$$


Where A means the area of plates, $\mathrm{d}$ means the distance between the two plates, and e means the permitivity of the material. Q refers to the electric charge and it is the amount of electricity a certain object has, and is divided into a positive charge and a negative charge. $\mathrm{C}$ is inversely proportional to the distance of the two plates and is proportional to the area of the material and the dielectric constant between two plates.

Two types of textile-based pressure sensors were developed; one for performance evaluation and the other for feasibility test during ascending/descending the stairs as illustrated in Fig. 2. Fig. 2 (a) shows the structure of a pressure sensor made for performance evaluation and it consists of two layers (a sensor layer and a ground layer). Fig. 2 (b) shows the structure of an insole-type pressure sensor. The sensor for performance evaluation was made with a single channel and the size of the insole was $5 \times 5 \mathrm{~cm}^{2}$. The insole type pressure sensor for feasibility test was built with 10 channels and its size was $270 \mathrm{~mm}$ as illustrated in Fig. 2 (c).

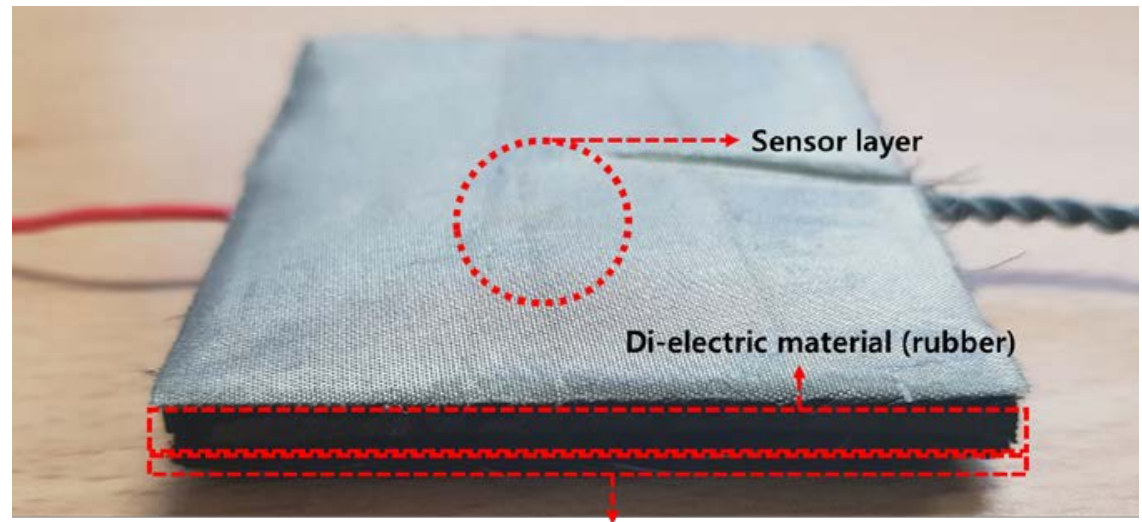

Ground layer

(a)

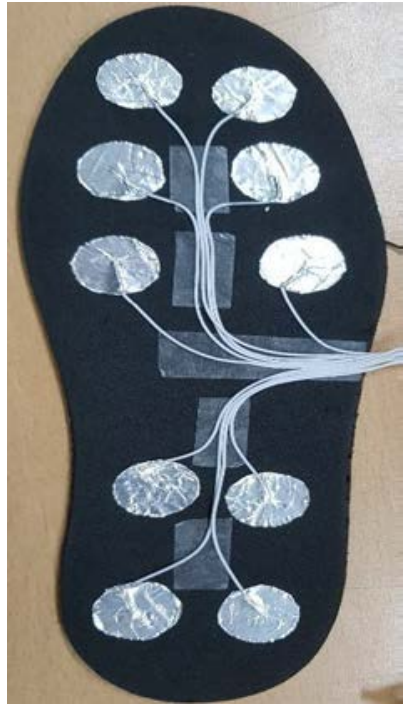

(b)

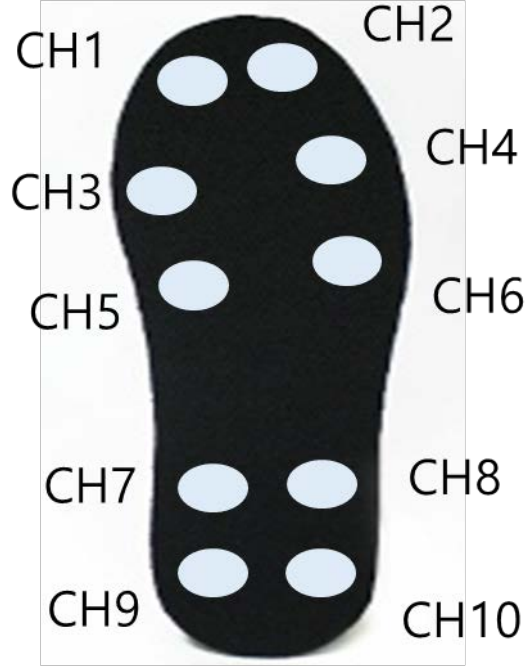

(c)

Fig. 2. Structure of the proposed pressure sensors, (a) performance test type, (b) insole type, (c) sensor location 


\subsection{Capacitance measurement and monitoring system}

To measure the capacitance changes during gait, we develoepd a capacitance measurement system as illustrated in Fig. 3. Fig. 3 (a) shows the safety shoes integrated with capacitance measurement system and Fig. 3 (b) shows the structure of printed circuit board (PCB) of our proposed system. The size of PCB was $2.3 \times 3.3 \mathrm{~cm}$ and the operation power was 3.7 V. For micro processor unit (MCU), STM32 series was used and for analog to digital signal conversion, MPR121QR2 sensor was used. Data were sampled at $100 \mathrm{~Hz}$. We used Bluetooth communication to transfer data between the capacitance measurement board and C\# capacitance moniotring system. The baudrate was set up at 115200 bps (bit per second).
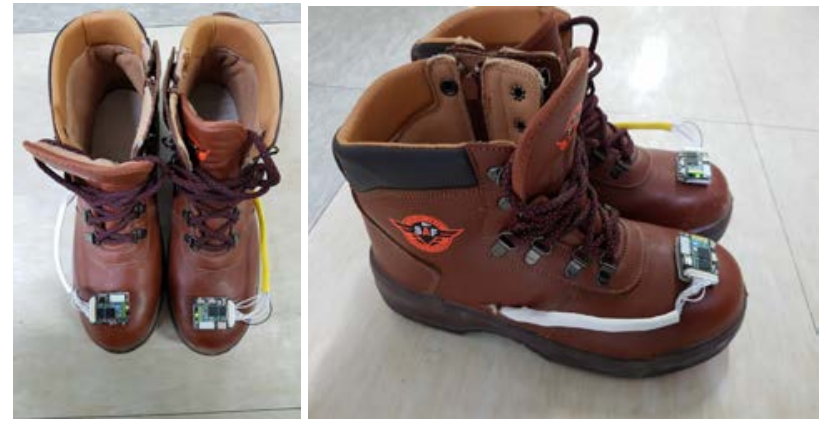

(a)

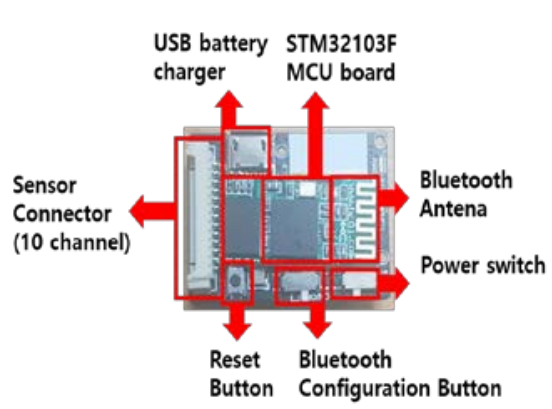

(b)

Fig. 3. Capacitance measurement system, (a) safety shoes integrated with capacitance measurement system, (b) capacitance measurement PCB

Fig. 4 shows the capacitance monitoring system. It was developed using $\mathrm{C \#}$ and was designed to receive data from all 20 channels of the insole sensors (10 from each foot). Capacitance monitoring system shows the waveform of the data collected in real time and each window shows the capacitance values from 10 channels (from each foot). The UI component includes a section with the list of port numbers and baudrate information, connect/disconnect button, and recording start/end (save) button. Data can be stored as a text file (100 samples per minute) and the raw data text file includes a time stamp (yy-dd-hh-mm-ss), where yy refers to the year, dd the day, hh the hour, mm the minute, and ss the second.

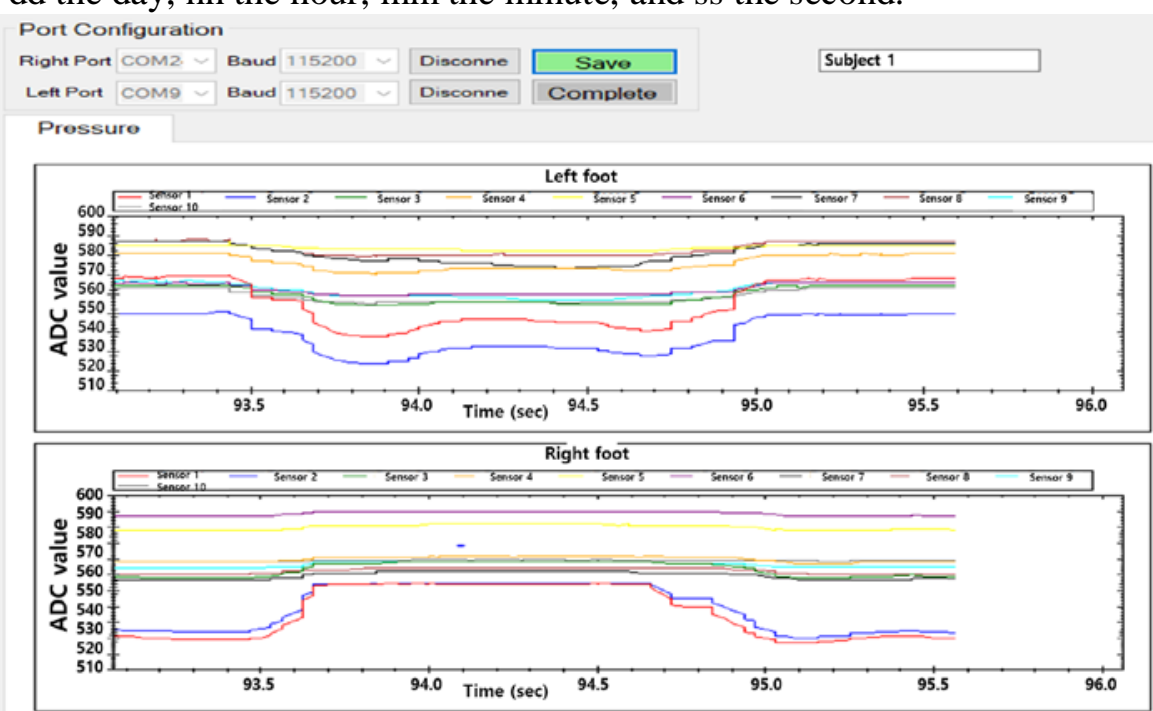

Fig. 4. Capacitance monitoring system 


\subsection{Signal processing}

Data from each set of 10 channels measured from each side of the foot were added together to form one signal. Then, fast fourier transform (FFT) was performed using Matlab2015a to check the frequency component of the measured signal from the developed system and to confirm the frequency components to be distributed between 0 to $3 \mathrm{~Hz}$ as shown in Fig. 5 . Pre-processing of the data was performed by applying the $4^{\text {th }}$ low-pass filter with a cut-off frequency of $3 \mathrm{~Hz}$.

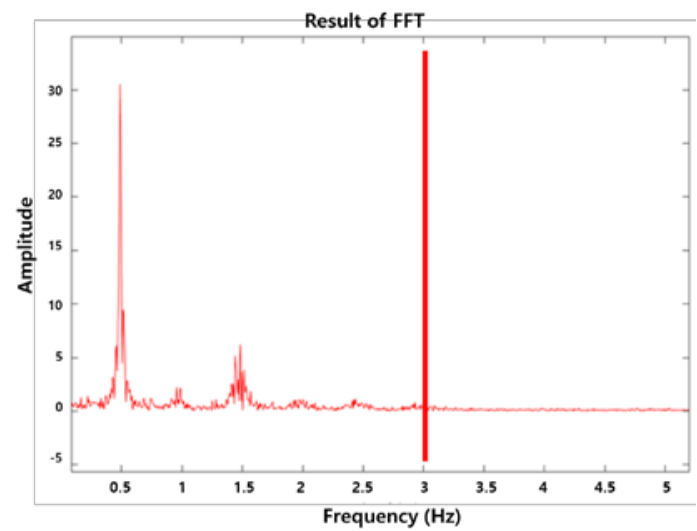

Fig. 5. Results of fast fourier transform analysis

We applied moving average filter ( $\mathrm{n}=5$ samples) using Equation 2 to minimize the noise component of the data during stair ascending/descending, and then smoothing was performed (Fig. 6). After pre-processing, the high peaks were detected using the local maxima algorithm (Fig. 7). Local maxima algorithm is a heuristic algorithm based on hill climbing search and it picks out the highest value in the selected area. A peak is defined when there is no other higher value.

$$
y[i]=\frac{\sum_{j=1}^{M-5} x_{i}-M+j}{M}
$$

Where, $\mathrm{y}[\mathrm{i}]$ is the output and $\mathrm{M}$ is the number of used points in moving average.

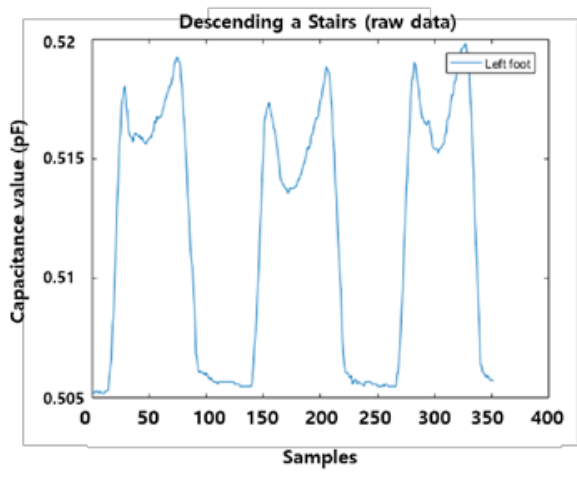

(a)

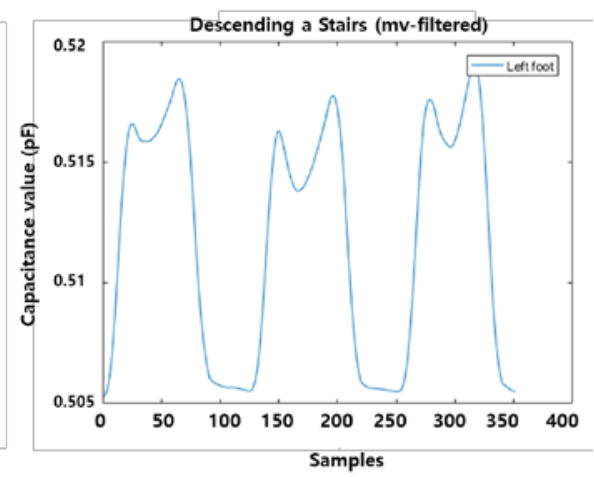

(b)

Fig. 6. Results of moving average filter on the data collected during stair descending, (a) raw data, (b) filtered data 


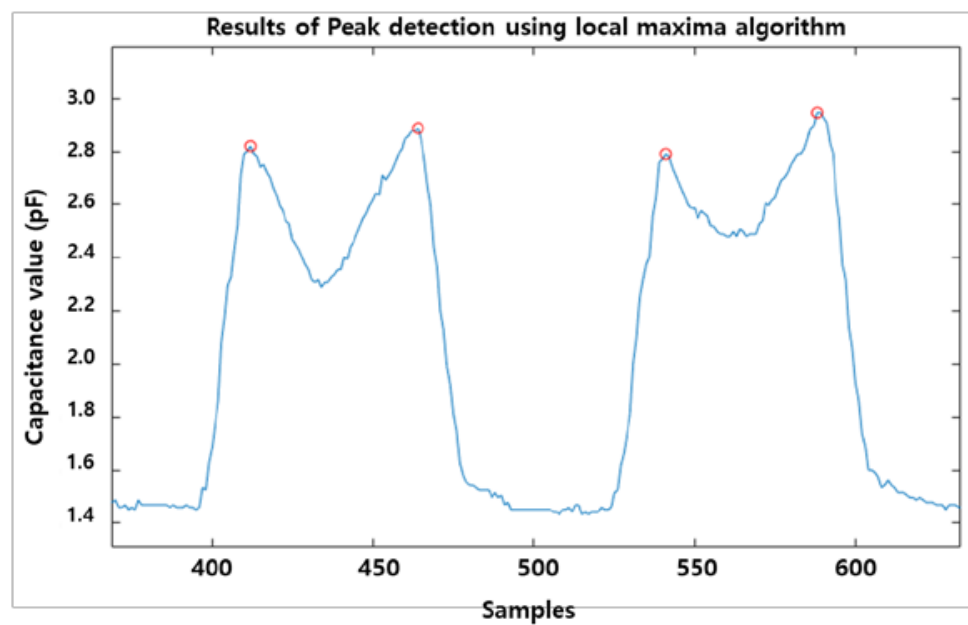

Fig. 7. Results of peak detection using local maxima algorithm

\subsection{Feature extraction}

Data collected from the proposed sensor were analyzed by 10-fold cross-validation method, which identified stair ascending and descending activities. A total of 12 feafures were selected for analysis as illustrated in Fig. 8.

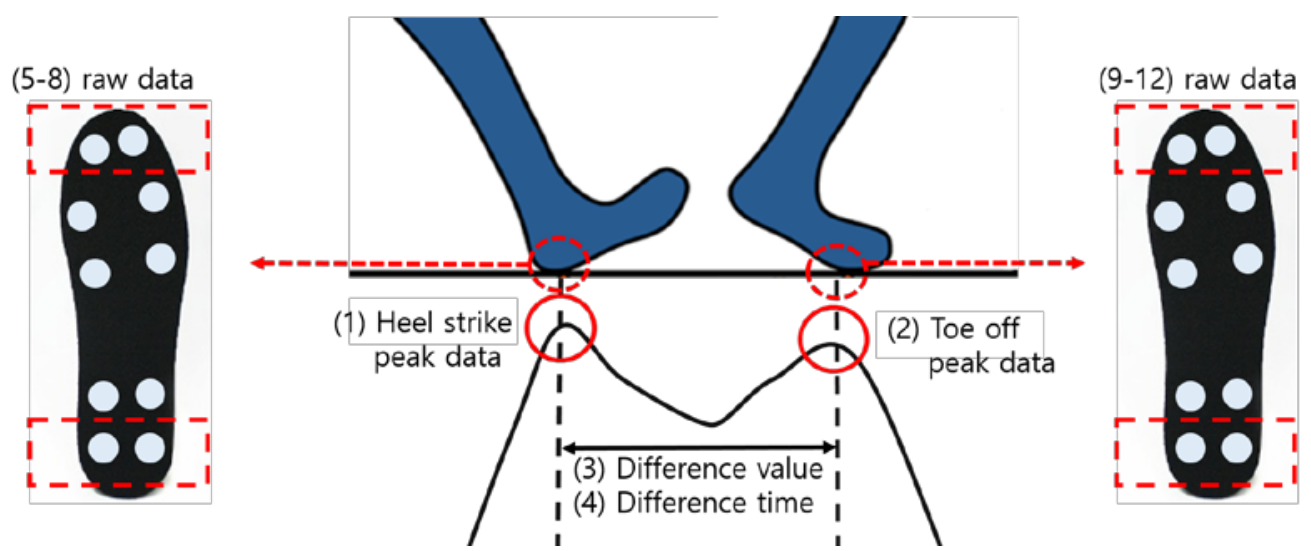

Fig. 8. Features for data analysis

The features analyzed by weka assessment tool were as follows : (1) the highest peak of heel strike from summation of 10 channels, (2) the highest peak of toe off from summation of 10 channels, (3) pressure difference between heel strike and toe off, (4) time intervals between heel strike and toe off, (5-8) raw data from channels 1, 2, 9, 10 at heel strike, and (9-12) raw data from channels 1, 2, 9, 10 at toe off. 


\subsection{Experimental protocol}

The experimental protocol was composed of two sections. The first was performance evaluation of our textile pressure sensor and the second section was testing the feasibility of our sensor in identifying the difference between stair ascending and descending.

\subsubsection{Resolution evaluation using load cell tensile compressor}

Resolution of the proposed sensor was evaluated by three consecutive experiments using load cell tensile compressor; model MCT-1150 (A\&D Company, Tokyo, Japan) as illustrated in Fig. 9. In order to measure the capacitance value in real time according to change of the distance and pressure count, the capacitance value was measured using the LCR meter (LCR-8110G, GWInstek, New Taipei City, Taiwan).

(1) Test 1 : The textile pressure sensor was placed between two conductive textiles and the charge in capacitance was measured by narrowing the distance between the two plates every $0.1 \mathrm{~mm}$.

(2) Test 2 : The same pressure was applied to the developed sensor for 5,000 times with a force of $46 \mathrm{~N}$ to evaluate the consistency of the measured values.

(3) Test 3 : Linearity of the collected data was examined with the same weight for 10 times from $1 \mathrm{~N}$ to $46 \mathrm{~N}$, in increments of $1 \mathrm{~N}$ ( $1 \mathrm{~N}$ is equal to $9.8 \mathrm{~kg})$. The MCT-1150 model has a maximum range of $51 \mathrm{~N}$, but $46 \mathrm{~N}$ was selected because when the plates get too close and touch each other, the data output becomes inaccurate. Our sensor was to be placed in insoles; considering that the pressure would rise when the sensor is worn inside the shoes, $46 \mathrm{~N}$ was considered the maximum force meaningful to be tested.

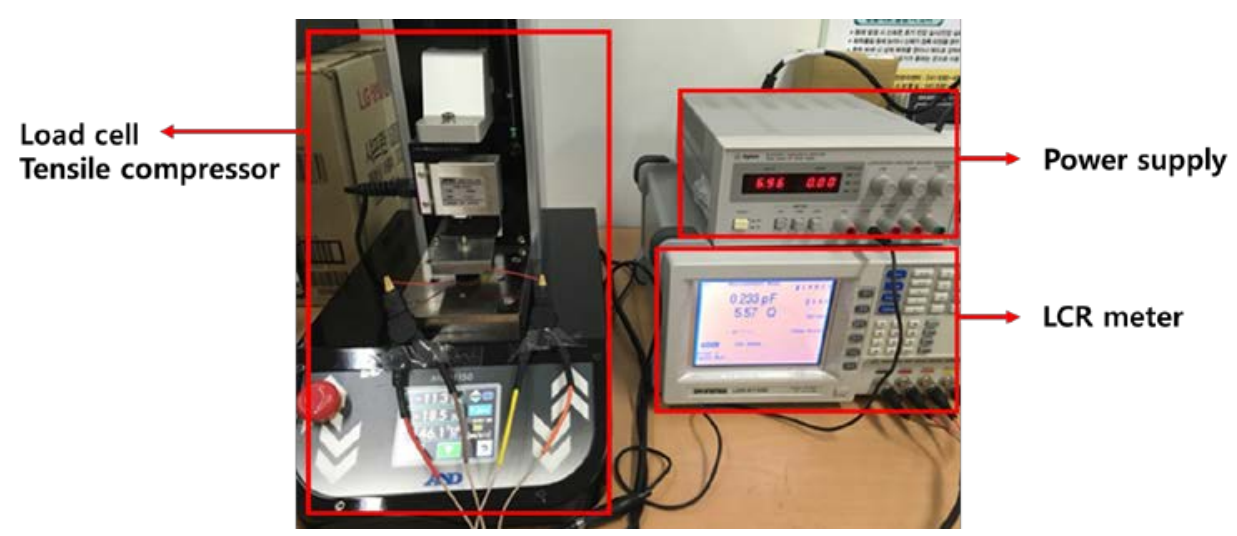

Fig. 9. Resolution test setting

\subsubsection{Subject characteristics}

Five young, healthy male subjects were included in this preliminary study. Their average age was 28.40 ( $\pm 3.36 \mathrm{SD}$ ) years and the average BMI was 25.40 ( $\pm 2.24 \mathrm{SD}$ ). None of the participants had a medical history of lower extremity injury and pathologic symptoms including fracture, sprain, musculoskeletal disease, pain, neurological symptoms, muscle 
weakness, limited range of motion in the joints. All subjects received a 5-minute pre-training before participating in the experiment for familiarization of the experimental protocol and the experiment procedure was thoroughly explained for clear understanding. The experiment was conducted after obtaining consent from all subjects in writing. Subjects continuously ascended and descended a total of 22 stair cases in a comfortable speed each person chose.

Table 1. Subject Characteristics

\begin{tabular}{cccccc}
\hline Sub No. & Age & $\begin{array}{c}\text { Weight } \\
(\mathrm{kg})\end{array}$ & $\begin{array}{c}\text { Height } \\
(\mathrm{cm})\end{array}$ & $\begin{array}{c}\text { BMI } \\
\text { (Body Mass Index) }\end{array}$ & Sex \\
\hline 1 & 26 & 70 & 178 & 22.09 & $\mathrm{M}$ \\
2 & 27 & 80 & 172 & 27.04 & $\mathrm{M}$ \\
3 & 32 & 75 & 171 & 25.64 & $\mathrm{M}$ \\
4 & 32 & 92 & 182 & 27.77 & $\mathrm{M}$ \\
5 & 25 & 75 & 175 & 24.48 & $\mathrm{M}$ \\
AVG & 28.40 & 78.4 & 175.6 & 25.40 & \\
SD & 3.36 & 8.38 & 8.38 & 2.24 & \\
\hline
\end{tabular}

\subsubsection{Feasibility test for identifying stair ascending and descending}

The morhologies of collected data were analyzed to test whether stair ascending and descending motions were identifiable as shown in Fig. 10. We used k-Nearest Neighborhood (k-NN) algorithm and differentiated stair ascending and descending movements using 10-fold cross-validation method of weka assessment tool. Normal walking data $(20 \mathrm{~m})$ were additionally collected as reference data.

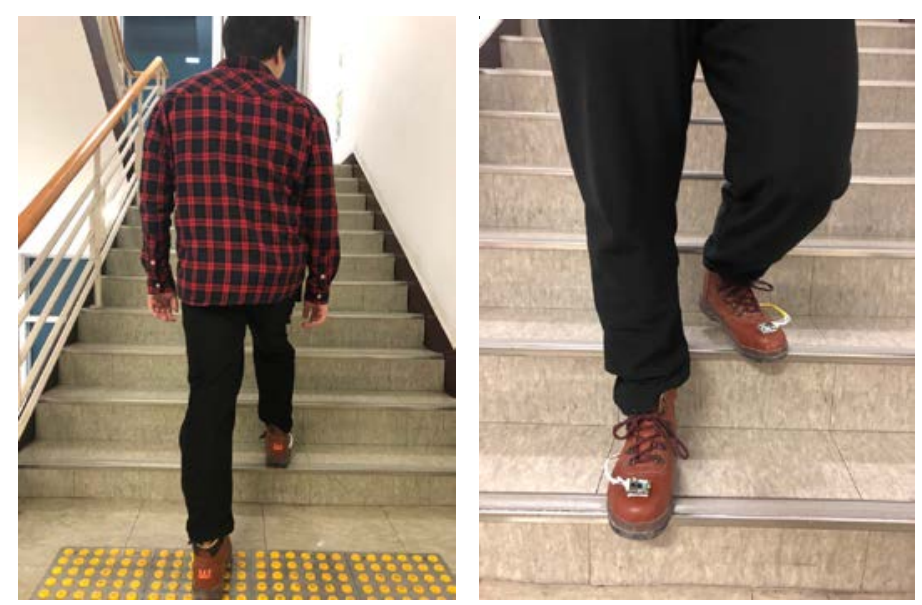

Fig. 10. Experiment environment 


\section{Results}

\subsection{Results of sensor performance evaluation}

The results of resolution performance test by using a load cell tensile compressor are shown in Table 2. As the distance between the two plates narrowed, the capacitance value was found to increase. The experiments confirmed that distance and capacitance were inversely proportional. As the distance increases by $1 \mathrm{~mm}$, the capacitance value decreases by $0.07 \mathrm{pF}$ in average (SD: $0.03 \mathrm{pF}$ ).

Table 2. Capacitance values at different distances between two plates

\begin{tabular}{|c|c|c|c|}
\hline Distance (mm) & Capacitance (pF) & Distance (mm) & Capacitance (pF) \\
\hline \hline 7.0 & 1.46 & 5.7 & 2.14 \\
\hline 6.9 & 1.52 & 5.6 & 2.21 \\
\hline 6.8 & 1.59 & 5.5 & 2.29 \\
\hline 6.7 & 1.64 & 5.4 & 2.37 \\
\hline 6.6 & 1.68 & 5.3 & 2.44 \\
\hline 6.5 & 1.73 & 5.2 & 2.50 \\
\hline 6.4 & 1.78 & 5.1 & 2.62 \\
\hline 6.3 & 1.82 & 5.0 & 2.78 \\
\hline 6.2 & 1.88 & 4.9 & 2.90 \\
\hline 6.1 & 1.92 & 4.8 & 3.04 \\
\hline 6.0 & 1.92 & 4.7 & 3.21 \\
\hline 5.9 & 1.97 & 4.6 & 3.30 \\
\hline 5.8 & 2.05 & 4.5 & 3.40 \\
\hline
\end{tabular}

Trend equation for the capacitance value according to the distance changes was derived as illustrated in Fig. 11. The derived trend formula had $\mathrm{R}^{2}$ equal to 0.99 and the fourth order polynomial $y=05 E-06 x^{4}+0.0004 x^{3}-0.0057 x^{2}+0.0803 x+1.3838$.

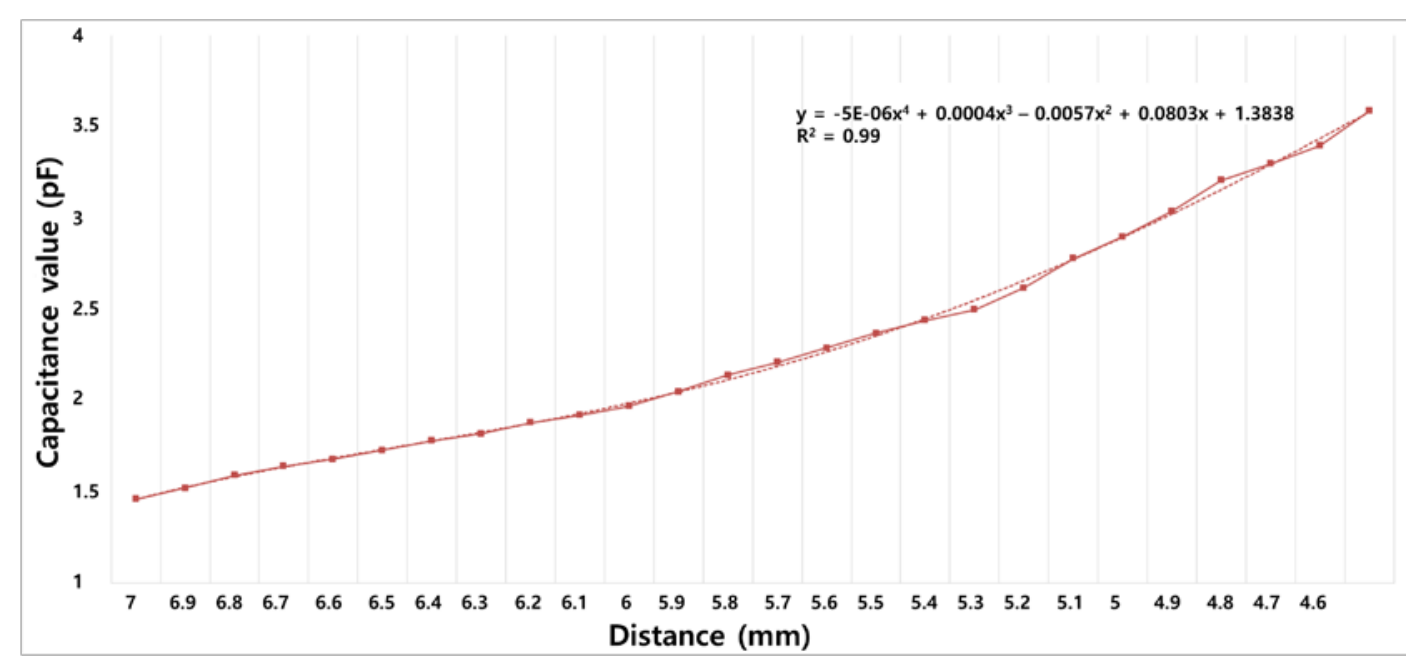

Fig. 11. Results of capacitance and trend equation of the proposed sensor according to distance

Consistency of the measured values while loading $46 \mathrm{~N}$ of force for 5,000 times is shown in Table 3. Average pressure was $2.4 \mathrm{pF}$ with standard deviation of $0.06 \mathrm{pF}$. 
Table 3. Consistency of the sensor capacitance values

\begin{tabular}{|c|c|c|c|}
\hline $\begin{array}{c}\text { Pressure } \\
\text { Loading Count }\end{array}$ & Capacitance (pF) & $\begin{array}{c}\text { Pressure } \\
\text { Loading Count } \\
\end{array}$ & Capacitance (pF) \\
\hline 0 & 2.4 & 2600 & 2.4 \\
\hline 100 & 2.3 & 2700 & 2.4 \\
\hline 200 & 2.5 & 2800 & 2.4 \\
\hline 300 & 2.4 & 2900 & 2.5 \\
\hline 400 & 2.4 & 3000 & 2.5 \\
\hline 500 & 2.4 & 3100 & 2.5 \\
\hline 600 & 2.4 & 3200 & 2.4 \\
\hline 700 & 2.5 & 3300 & 2.5 \\
\hline 800 & 2.5 & 3400 & 2.4 \\
\hline 900 & 2.6 & 3500 & 2.4 \\
\hline 1000 & 2.4 & 3600 & 2.4 \\
\hline 1100 & 2.4 & 3700 & 2.4 \\
\hline 1200 & 2.4 & 3800 & 2.4 \\
\hline 1300 & 2.4 & 3900 & 2.4 \\
\hline 1400 & 2.5 & 4000 & 2.4 \\
\hline 1500 & 2.5 & 4100 & 2.5 \\
\hline 1600 & 2.4 & 4200 & 2.4 \\
\hline 1700 & 2.4 & 4300 & 2.4 \\
\hline 1800 & 2.4 & 4400 & 2.4 \\
\hline 1900 & 2.5 & 4500 & 2.4 \\
\hline 2000 & 2.6 & 4600 & 2.4 \\
\hline 2100 & 2.5 & 4700 & 2.5 \\
\hline 2200 & 2.5 & 4800 & 2.5 \\
\hline 2300 & 2.4 & 4900 & 2.5 \\
\hline 2400 & 2.5 & 5000 & 2.4 \\
\hline 2500 & 2.4 & & \\
\hline Avg & 2.4 & SD & 0.06 \\
\hline
\end{tabular}

Fig. 12 shows the results of linearity test after repeatedly loading the same pressure for 10 times, and gradually increasing the pressure from $1 \mathrm{~N}$ to $46 \mathrm{~N}$ in increments of $1 \mathrm{~N}$. The trend equation derived shows $\mathrm{R}^{2}$ equaling $0.99(\mathrm{y}=0.0216 \mathrm{x}+1.3665)$.

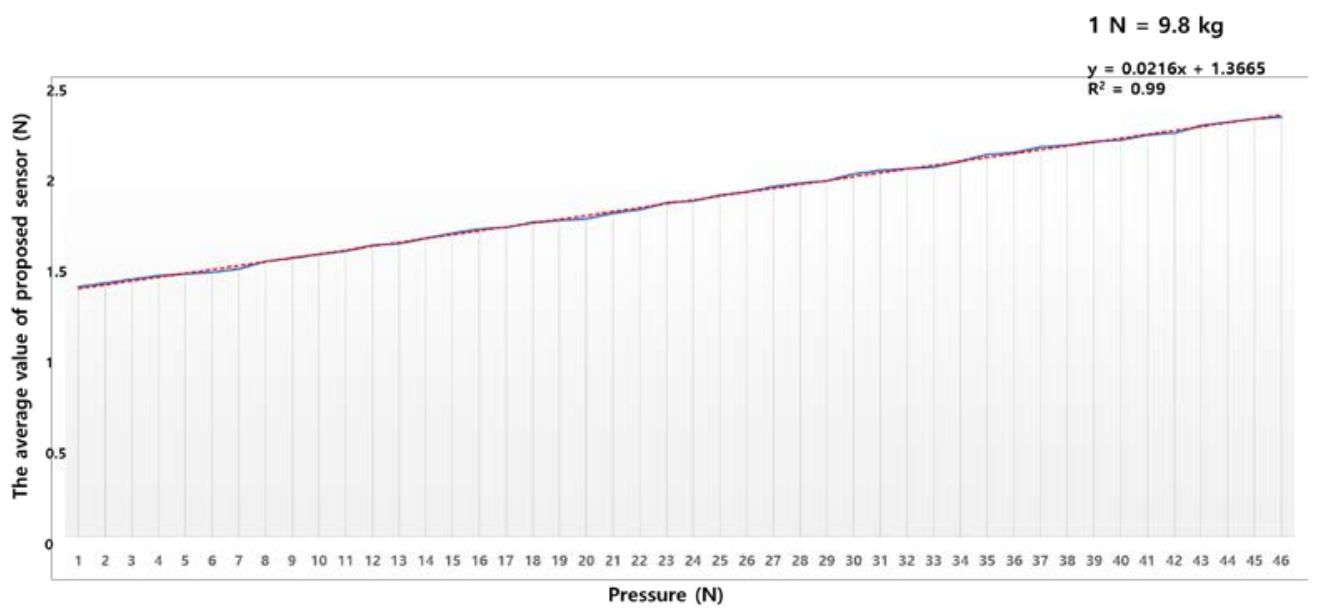

Fig. 12. Linearity of capacitance value from $1 \mathrm{~N}$ to $46 \mathrm{~N}$ in increments of $1 \mathrm{~N}$ of pressure 


\subsection{Results of feasibility test for identifying stair ascending and descending}

Fig. 13 (a) presents the morphology of stair descending detected by the insole pressure sensor, where A $(0.516 \mathrm{pF})$ was detected from the heel and $\mathrm{B}(0.516 \mathrm{pF})$ from the toe area. When descending the stairs, A and B peak points were found to be almost the same. Fig. 13 (b) shows the morphology of ascending the stairs. The peak value of $\mathrm{B}(0.518 \mathrm{pF})$ was higher than that of A $(0.514 \mathrm{pF})$. During stair ascending, subjects exerted more force on the toe area.
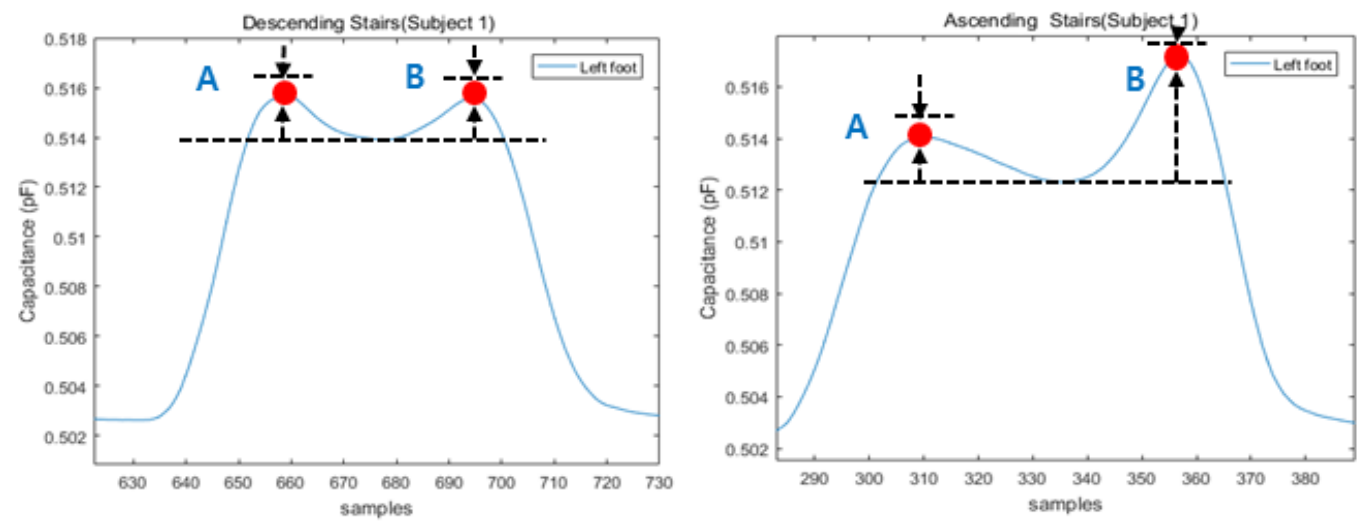

Fig. 13. Results of gait signal morphology during (a) descending, (b) ascending

Table 4 and 5 summarize the accuracy for ascending and descending the stairs using k-NN algorithm. The precision of ascending stairs was 0.872 and descending stairs was 0.909 .

Table 4. Detailed accuracy for ascending and descending stairs

\begin{tabular}{cccccc}
\hline Activity & TP rate & FP rate & Precision & Recall & F-measure \\
\hline Walking & 0.925 & 0.026 & 0.904 & 0.925 & 0.914 \\
Ascending stairs & 0.924 & 0.089 & 0.872 & 0.924 & 0.897 \\
Descending stairs & 0.844 & 0.055 & 0.909 & 0.844 & 0.876 \\
\hline
\end{tabular}

Table 5. onfusion matrix for ascending and descending stairs

\begin{tabular}{ccccc}
\hline & & \multicolumn{3}{c}{ Predicted Class } \\
\cline { 2 - 5 } & & $\mathrm{a}$ & $\mathrm{b}$ & $\mathrm{c}$ \\
\hline \multirow{3}{*}{ Actual Class } & $\mathrm{a}$ & 123 & 6 & 4 \\
& $\mathrm{~b}$ & 2 & 231 & 17 \\
Precision & $\mathrm{c}$ & 11 & 28 & 211 \\
& & 0.904 & 0.872 & 0.909 \\
\hline a : walking, b : ascending stairs, c : descending stairs
\end{tabular}

\section{Discussion}

This study aimed to develop a textile-based insole pressure sensor (performance test type and feasibility test type) for real-time monitoring and warning system for the safety of construction workers. After sensor performance test, a pilot feasibility test was performed to 
examine whether the proposed sensor was able to identify ascending and descending motions on the stairs.

The results of our sensor performance test showed that at every distance increase in increments of $1 \mathrm{~mm}$ (from $7 \mathrm{~mm}$ to $4.5 \mathrm{~mm}$ ), the capacitance value was decreased by $0.07 \mathrm{pF}$ (SD : $0.03 \mathrm{pF}$ ). The highest capacitance of $3.40 \mathrm{pF}$ was found in $4.5 \mathrm{~mm}$ thickness in our study. This could be used as a reference data for insole-type pressure sensor developers who are seeking or considering capacitive sensor for an alternative. In addition, the existing studies on the development of pressure sensors for gait measurement presented that more research is needed to find the optimum thickness of pressure sensing insoles. Our findings would provide a possible solution for developing more reliable insole-type textile pressure sensors. The results of the consistency test of our proposed sensor confirmed that our sensor has a high consistency (AVG : $2.4 \mathrm{pF}, \mathrm{SD}: 0.06 \mathrm{pF}$ ).

We chose the k-NN algorithm for feature analysis, because our proposed sensor was previously proved to have high resolution (less noise) when compoared with F-scan sensor [32]. The accuracy level of k-NN algorithm normally decreases when the feature variables are unrelated, have noise, or when the feature size matching is considered not important [33]. In this study, the precision of stair ascending and descending identified by k-NN algorithm confirmed high performance of our proposed sensor [34]. A study by Storm et al. (2015) reported high precision (99.2\%) results of their sensor in differentiating ascending and descending stairs [35]. Their results were based on 8 different types of sensors worn over the entire body, which would be relatively more accurate in detecting the motions, but we tried using just one pair of insole sensors to reduce the cost for the future users and to make the wearing of the sensor more practical. Our results were confirmed to have as high performance compared to the previous study results (ascending 87.2\%, descending 90.9\%). Using less number of sensors is a key to reduce cost and increase work efficiency when the purpose is to be used in real life setting.

For the feasibility test of our sensor, weight shifting patterns during stair-climbing were analyzed based on the plantar pressure data. The results of capacitance values detected during stair descending showed no significant peak pressure difference between the heel and toe area. This was due to the entire foot being in contact with the surface of the stair case because the subjects were unconsciously trying to not fall off the stairs. Conversely during ascending, the force exerted on the toe area of the foot was larger than that of the heel area. Such morphology was found, because when climbing the stairs, the center of gravity of the human body is naturally directed forward and thus stronger force is applied to the forefoot area. This also is related to keeping the body from not falling. The results of this study were congruent with those of the previous studies that performed similar research [36].

Our sensor and monitoring system differentiated stair ascending from descending, and weight shifting changes during the activity were detected. This pilot test confirmed the feasibilty of the developed system to be used as fall prevention and danger warning system for construction worksites. Falling from the stairs is caused by momentary loss of balance, use of inappropriate weight shifting strategy, wrongful posture control during lifting or lowering of the body, and structural abnormality in the foot and lower extremity. These factors can be indirectly assessed and diagnosed by distribution and intensity changes in plantar pressure, therefore the results of this study are meaningful. Further studies with a larger number of subjects are needed, and testing various construction work-simulated activities would build meaningful standards for plantar pressure distribution and intensity. Moreover, individualized normal range of motion data can serve as a standard in detecting and alarming when any extreme movements out of normal range of motion is found. 
Although we have developed a cost-effective, wearable textile pressure sensor and obtained meaningful results from the performance test and feasibility pilot, our research has a few limitations. First, the gait data are transmitted to the monitoring system via Bluetooth communications in real time, so the battery is consumed quickly. For this reason, data analyzing functions may not last for a long time, but battery life test was not performed in this study. Secondly, generalization of the results of this study may be difficult because the number of subjects was small. Lastly, the performance test was conducted in a laboratory and did not consider temperature and humidity factors.

In our future studies, we plan to recruit a larger number of subjects and apply our sensor in detecting various construction work-related movements and a real-life loading test can be designed based on the derived trend equation. As the results of this study showed feasibility, further study in various environments, considering changes in the temperature and humidity, at different heights and over uneven grounds could make better use of the developed sensor and monitoring system for construction workers.

\section{Conclusion}

We developed a light-weight, cost-effective, wearable insole-type textile pressure sensor with a Bluetooth-based monitoring system for predicting and alarming stairway falls of construction workers. The insole sensor was highly reliable and accurate in receiving and analyzing gait data, and could identify the difference between stair ascending and descending. Our proposed sensor and monitoring system are expected to detect more various activities in real time and prevent accidents by smart safety management of the construction sites.

\section{Acknowledgement}

This study was supported by Basic Research Program through the National Research Foundation of Korea (NRF) funded by the Ministry of Education (NO. 2017R1A2B1011776) and was supported by the Soonchunhyang University.

\section{References}

[1] K. A. Scott, G. G. Fisher, A. E. Baron, E. Tompa, L. Stallones and C. DiGuiseppi, "Same-level fall injuries in US workplaces by age group, gender, and industry," American journal of industrial medicine, vol. 61, no. 2, pp. 111-119, February, 2018. Article (CrossRef Link).

[2] T. K. Courtney, S. Matz and B.S. Webster, "Disabling occupational injury in the US construction industry, 1996," Journal of Occupational and Environmental Medicine, vol. 44, no. 12, pp. 1161-1168, December, 2002. Article (CrossRef Link).

[3] D. Smith, B. Veitch, F. Khan and R. Taylor, "Understanding industrial safety: Comparing Fault tree, Bayesian network, and FRAM approaches," Journal of Loss Prevention in the Process Industries, vol. 45, pp. 88-101, January, 2017. Article (CrossRef Link).

[4] T. B. Leamon and P. L. Murphy, "Occupational slips and falls: more than a trivial problem," Journal of Loss Prevention in the Process Industries, vol. 38, no. 3, pp. 487-498, July, 2010. Article (CrossRef Link).

[5] K. Kemmlert and L. Lundholm, "Slips, trips and falls in different work groups - with reference to age and from a preventive perspective,” Applied Ergonomics, vol. 32, no. 2, pp. 149-153, April, 2001. Article (CrossRef Link).

[6] L. Layne and K. Pollack, "Nonfatal occupational injuries from slips, trips, and falls among older workers treated in hospital emergency departments, United States 1998," American journal of 
industrial medicine, vol. 46, no. 1, pp. 32-41, July, 2004. Article (CrossRef Link).

[7] P. Raina, N. Sohel, M. Oremus, H. Shannon, P. Mony, R. Kumar, et al., "Assessing global risk factors for non-fatal injuries from road traffic accidents and falls in adults aged 35-70 years in 17 countries: a cross-sectional analysis of the Prospective Urban Rural Epidemiological (PURE) study,” Inj. Prev., vol. 22, no. 2, pp. 92-98, April, 2016. Article (CrossRef Link).

[8] S. Heinrich, K. Rapp, U. Rissmann, C. Becker, H.H. Konig, "Cost of falls in old age: a systematic review,” Osteoporos. Int., vol. 21, no. 6, pp. 891-902, June, 2010. Article (CrossRef Link).

[9] J. K. Startzell, D. A. Owens, L. M. Mulfinger and P. R. Cavanagh, "Stair negotiation in older people: a review,” J. Am. Geriatr. Soc., vol. 48, no. 5, pp. 567-580, May, 2000. Article (CrossRef Link).

[10] M. E. Tinetti, M. Speechley and S. F. Ginter, "Risk factors for falls among elderly persons living in the community,” N. Engl. J. Med., vol. 319, pp. 1701-1707, December, 1988. Article (CrossRef Link).

[11] D. L. Gill, B. C. Kelley, K. Williams and J. J. Martin, “The relationship of self-efficacy and perceived well-being to physical activity and stair climbing in older adults,” Res. Q. Exerc. Sport, vol. 65, no. 4, pp. 367-371, February, 2013. Article (CrossRef Link).

[12] S. M. Ghodsi, B. S. Roudsari, M. Abdollahi and M. Shadman, "Fall-related injuries in the elderly in Tehran,” Injury, vol. 34, no. 11, pp. 809-814, November, 2003. Article (CrossRef Link).

[13] S. W. Muir, K. Berg, B. M. Chesworth, N. Klar and M. Speechley, "Modifiable risk factors identify people who transition from non-fallers to fallers in community-dwelling older adults: a prospective study,” Physiother. Can., vol. 62, no. 4, pp. 358-367, October, 2010. Article (CrossRef Link).

[14] L. A. Talbot, R. J. Musiol, E. K. Witham and E. J. Metter, "Falls in young, middle-aged and older community dwelling adults: perceived cause, environmental factors and injury,” BMC Public Health, vol. 5, pp. 86, August, 2005. Article (CrossRef Link).

[15] B. Kool, S. Ameratunga, W. Hazell and A. Ng, "Unintentional falls at home among young and middle-aged New Zealanders resulting in hospital admission or death: context and characteristics," N. Z. Med. J., vol. 123, pp. 75-84, June, 2010.

[16] D. C. Malta, M. M. Silva, M. D. Mascarenhas, N. N. Sa, O. L. Morais Neto, R. T. Bernal, et al., "The characteristics and factors of emergency service visits for falls," Rev. Saude Publica, vol. 46, no. 1, pp. 128-137, February, 2012. Article (CrossRef Link).

[17] J. V. Jacobs, "A review of stairway falls and stair negotiation: Lessons learned and future needs to reduce injury,” Gait \& Posture, vol. 49, pp. 159-167, September, 2016. Article (CrossRef Link).

[18] P. Li, R. Meziane, M. J. D. Otis, H. Ezzaidi and P. Cardou, “A Smart Safety Helmet using IMU and EEG sensors for worker fatigue detection,” in Proc. of 2014 IEEE International Symposium on Robotic and Sensors Environments (ROSE) proceedings, 14775980, October 16-18, 2014. Article (CrossRef Link).

[19] S. H. Kim, C. W. Wang, S. D. Min and S. H. Lee, "Safety Helmet Wearing Management System for Construction Workers Using Three-Axis Accelerometer Sensor,” Appl. Sci., vol. 8, no. 12, pp. 2400, November, 2018. Article (CrossRef Link).

[20] K. H. Yang, C. R. Ahn and H. S. Kim, "Validating ambulatory gait assessment technique for hazard sensing in construction environments,” Automation in Construction, vol. 98, pp. 302-309, February, 2019. Article (CrossRef Link).

[21] A. Albert, M. R. Hallowell, B. Kleiner, A. Chen and M. Golparvar-Fard, "Enhancing construction hazard recognition with high-fidelity augmented virtuality,” J. Constr. Eng. Manag., vol. 140, no. 7, 04014024, April, 2014. Article (CrossRef Link).

[22] A. Albert, M. Hallowell and B. Kleiner, "Enhancing construction hazard recognition and communication with energy-based cognitive mnemonics and safety meeting maturity model: multiple baseline study,” J. Constr. Eng. Manag., vol. 140, no. 2, 04013042, February, 2014. Article (CrossRef Link).

[23] G. H. Cattledge, A. Schneiderman, R. Stanevich, S. Hendricks and J. Greenwood, "Nonfatal occupational fall injuries in the West Virginia construction industry," Accid. Anal. Prev., vol. 28, no. 5, pp. 665-663, September, 1996. Article (CrossRef Link). 
[24] Y. Liu, L. Nie, L. Liu and D. S. Rosenblum, "From action to activity: Sensor-based activity recognition,” Neurocomputing, vol. 181, pp. 108-115, March, 2016. Article (CrossRef Link).

[25] M. Shoaib, S. Bosch, O. D. Incel, H. Scholten and Paul J. M. Havinga, "A survey of Online Activity Recognition Using Mobile Phones,” Sensors, vol. 15, no. 1, pp. 2059-2085, January, 2015. Article (CrossRef Link).

[26] N. F. Ribeiro, and C. P. Santos, "An intuitive visual for a real-time monitoring system for human gait using IMUs," in Proc. of 2017 IEEE International Conference on Autonomous Robot Systems and Competitions (ICARSC), pp. 153-158, April 26-28, 2017. Article (CrossRef Link).

[27] P. Gupta and T. Dallas, "Feature Selection and Activity Recognition System Using a Single Triaxial Accelerometer," IEEE TRANSACTION ON BIOMEDICAL ENGINEERING, vol. 61, no. 6, pp. 1780-1786, June, 2014. Article (CrossRef Link).

[28] T. Gu, L. Wang, Z. Wu, X. Tao and J. Lu, "A Pattern Mining Approach to Sensor-Based Human Activity Recognition," IEEE Transaction on Knowledge and Data Engineering, vol. 23, no. 9, pp. 1359-1372, September, 2011. Article (CrossRef Link).

[29] A. Bulling, U. Blanke and B. Schiele, "A tutorial on human activity recognition using body-worn inertial sensors,” ACM computing Surveys, vol. 46, no. 3, pp. 1-33, January, 2014. Article (CrossRef Link).

[30] O. Banos, J. M. Galvez, M. Damas, H. Pomares and I. Rojas, "Window Size Impact in Human Activity Recognition,” Sensors, vol. 14, no. 4, pp. 6474-6499, April, 2014. Article (CrossRef Link).

[31] S. C. Mukhopadhyay, "Wearable Sensors for Human Activity Monitoring: A review," IEEE Sensors Journal, vol. 15, no. 3, pp. 1321-1330, March, 2015. Article (CrossRef Link).

[32] C. W. Wang, Y. Kim and S. D. Min, "Soft-Material-Based Smart Insoles for a Gait Monitoring System,” Materials, vol. 11, no. 12, pp. 2435, November, 2018. Article (CrossRef Link).

[33] T. Cover and P. Hart, "Nearest neighbor pattern classification," IEEE Trans. Inf. Theory, vol. 13, no. 1, pp. 21-27, January, 1967. Article (CrossRef Link).

[34] J. R. Kwapisz, G. M. Weiss and S. A. Moore, "Activity Recognition Using Cell Phone Accelerometers," ACM SIGKDD Explorations Newsletter, vol. 12, no. 2, pp. 74-82, December, 2010. Article (CrossRef Link).

[35] F. A. Storm, B. W. Heller and C. Mazza, "Step Detection and Activity Recognition Accuracy of Seven Physical Activity Monitors,” PLOS ONE, vol. 10, no. 3, pp. e0118723, March, 2015. Article (CrossRef Link).

[36] Y. Han, Y. Cao, J. Zhao, Y. Yin, L. Ye, X. Wang and Z. You, "A Self-Powered Insole for Human Motion Recognition,” Sensors, vol. 16, no. 9, pp. 1502, September, 2016. Article (CrossRef Link).

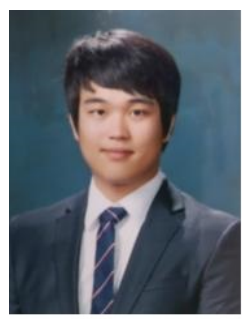

Changwon Wang received the BS and MS degrees in Medical IT Engineering from Soonchunhyang University in 2013 and 2015 respectively. He is currently a Ph.D. student as a member of the Medical System \& Device laboratory at the Soonchunhyang University. His research interests are Gait analysis, Biomedical engineering, Signal processing, and Smart healthcare.

E-mail: changwon@sch.ac.kr 


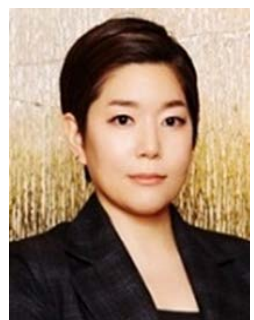

Young Kim is a registered physiotherapist and received the B.S and M.S. from the Department of Physical Therapy, Yonsei University in 2002 and 2006, respectively. After 2 years of post-doctoral fellowship at Yonsei U., she joined Soonchunhyang University as a Research Professor in 2016 and has been working at the Department of Medical IT Engineering from 2017. Her research area includes wearable feedback sensors for clinical treatments, mobile rehabilitative healthcare, and neuro-rehabilitation.

E-mail: ykim02@sch.ac.kr

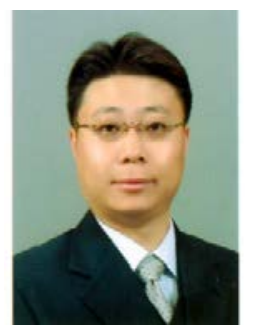

Seung-Hyun Lee is a Associate Professor, School of Architectural Engineering, Hongik University. He received his B.S 1996 Inha University, and his M.S 1999 University of Colorado at Boulder, Ph.D. 2003 University of Florida at Gainesville 2004 2008:Korea Institute of Construction Engineering, Senior Researcher. 2008 Current: Hongik University, Associate Professor. Interesting Research Area: Process Simulation, Productivity, Construction Information Technology, Image Processing, Automatic Data Acquisition.

E-mail: slee413@hongik.ac.kr

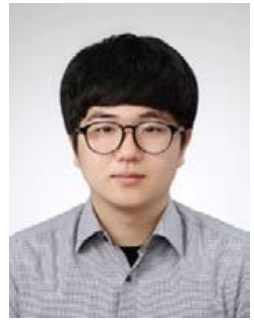

Nak-Jun Sung received the BS degrees in Computer Software Engineering from Soonchunhyaung University in 2016. He also received MS in Dept of Computer Science from Soonchunhyaung University in 2018. Now he is undertaking a Ph.D of computer science courses as a member of the computer graphics lab at Soonchunhyang University. His research interests are computer graphics, GPGPU, VR (Virtual Reality) and AR (Augmented Reality). E-mail: njsung@sch.ac.kr

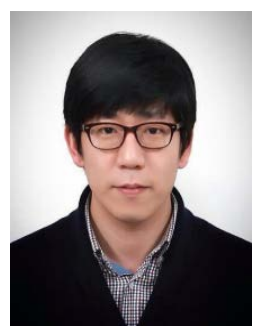

Se Dong Min received the M.S. and Ph.D. degrees in electrical and electronic engineering from the Department of Electrical and Electronics Engineering, Yonsei University, Seoul, in 2004 and 2010, respectively. He is currently an Associate Professor at the Department of Medical IT Engineering, Soonchunhyang University, Asan, Korea. His research area includes biomedical signal processing, healthcare sensor application, and mobile healthcare technologies. E-mail: sedongmin@sch.ac.kr

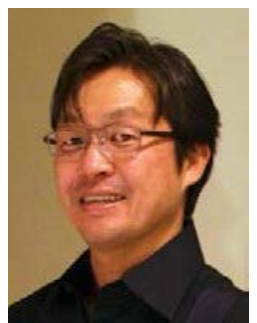

Min-Hyung Choi received his M.S. and Ph.D. from University of Iowa in 1996 and 1999 respectively. He joined the Computer Science and Engineering Department at the University of Colorado at Denver in 1999. Currently he is a Professor of Computer Science and the Director of Computer Graphics and Virtual Environments Laboratory. His research interests are in Computer Graphics, Scientific Visualization and Human Computer Interaction with an emphasis on physically-based modeling and simulation. E-mail: min.choi@ucdenver.edu 